\title{
COMÉRCIO E MEIO AMBIENTE: O IMPACTO AMBIENTAL SOBRE A ECONOMIA DO TOGO e DA ÁFRICA.
}

\author{
Omar Ouro-Salim ${ }^{1}$
}

Resumo:

Um dos principais desafios deste século tem sido a conciliação do crescimento econômico com a preservação ambiental, considerando-se o crescimento populacional e da produção de lixo a partir de descartáveis e produtos industrializados. Objetivando-se o desenvolvimento sustentável torna-se necessário a adoção de atitudes baseadas na aplicação dos princípios da política dos três (Rs) (Reduzir, Reciclar, Reutilizar) para o lixo produzido tornando-o útil, visando a preservação do meio ambiente e da qualidade de vida, a valorização da Natureza Humana, com base na educação ambiental. A gestão da coleta de lixo em área pobre visa à conscientização, mobilização, e participação permanente na proteção do meio ambiente, como exercício cidadania. $O$ projeto visa a destinação ecologicamente correta, reforçando as metas do desenvolvimento sustentável através da reciclagem do lixo inorgânico e ou reaproveitamento de mesmo através de processo de reutilização em oficinas de artesanato em benefício da comunidade e reaproveitamento do lixo orgânico através de processo da compostagem e geração de produtos úteis para a Sociedade. Além disso, mostrar as preocupações das empresas sobre a preservação do meio ambiente e como se dá essa mudança ecológica na África.

Palavras-chaves: Lixo, reciclagem, coleta seletiva, educação ambiental.

\section{INTRODUÇÃO:}

A república do TOGO é um pequeno país localizado bem na parte oeste da África. Hoje em dia, a preocupação do Governo Togolês é preservar o meio ambiente e criar o emprego e outras atividades econômicas através da reciclagem em todo lugar da nossa capital (LOMÉ).

A crescente preocupação com o meio ambiente tem sido frequentemente relatada tanto na literatura cientifica quanto nos diversos meios de comunicação. Conforme Brilhante e Caldas (1999) o meio ambiente é um dos temas relevantes na política governamental e uma grande preocupação dos cidadãos. Seja nos países

1 PPGGO - Programa de Pós Graduação / UFG/ RC, ouromar@yahoo.fr. 
desenvolvidos, ou em desenvolvimento, a consciência política e social da integração e a saúde humana é um fato.

A coleta seletiva de lixo objetiva a diminuição da poluição do ar, do solo e dos recursos hídricos, o reaproveitamento de matérias-primas, diminuindo a exploração das riquezas naturais como a extração de minérios e madeira, do mesmo modo que aponta para economia de energia.

Uma das marcas registradas da reciclagem nacional é priorizar a geração de emprego e renda para as populações mais pobres e garantir a sustentabilidade socioeconômica dos programas de coleta seletiva de resíduos sólidos urbanos (BORBAS et al. 1994).

A riqueza gerada por essa economia informal mostra que os trabalhadores da coleta não institucionalizada de lixo não aguardam uma solução para o problema do desemprego no país.

Este trabalho visa à integração de temas relacionados à conscientização e ao resgate da consciência da cidadania, com base na educação ambiental e na preservação de meio ambiente, não apenas em relação a natureza exterior, mas à valorização da própria Natureza Humana. Isto inclui:

-Alternativa ao desemprego, combate à violência e ao uso de drogas, a exploração do trabalho infantil; ás doenças relacionadas, direita ou indiretamente, ao lixo e a contaminação do meio ambiente.

-A valorização e preservação dos recursos naturais, do patrimônio público, da qualidade de vida e resgate da cidadania, integração comunitária e da sociedade como um todo, inclusão dos excluídos e produção de riquezas para a cidade.

Este projeto objetiva promover a educação ambiental, a reciclagem do lixo e da cidadania, estimulando hábitos de preservação do meio-ambiente, a cultura permanente da coleta seletiva do lixo e o reaproveitamento de sucatas e material orgânico. Isto levará à criação de empregos, cooperativas de produção e oficinas profissionalizantes, aumentando a renda autônoma de muitos excluídos.

Em síntese, o objetivo do projeto é a educação permanente do cidadão através da política dos três "Rs": Redução, Reutilização e Reciclagem do Lixo, visando sua interação, conscientização, mobilização e participação ativa e permanente na proteção do meio-ambiente, como exercício da cidadania.

O projeto enfatiza e propõe alternativas para o combate à violência e suas causas: o desemprego, a exploração do trabalho e prostituição infantil, as drogas, a falta de ocupação produtiva do adolescente etc. $O$ instrumento para este combate será a valorização de um tipo de riqueza até hoje ignorada pela opinião pública em nível nacional: a educação ambiental e o material reciclável e reaproveitável. 0 projeto visa divulgar e estimular a formação de novos hábitos culturais em nível nacional como internacional, valorizando a criação humana em seus aspectos artísticos, cultural, lúdico, econômico e social, estimulando assim o exercício e a reciclagem da cidadania, além disso, mostrar as preocupações das empresas sobre a preservação do meio ambiente e como se dá essa mudança ecológica na África.

\section{DESENVOLVIMENTO}

\subsection{BREVE CARATERIZAÇÃO ECONÔMICA DO TOGO}

A pequena economia do Togo é muito dependente da agricultura, tanto a comercial como a de subsistência. As atividades agrícolas empregam $65 \%$ da mãode-obra. O cacau, o café e o algodão representam juntos cerca de $40 \%$ das receitas com as exportações. O país é também o quarto maior produtor mundial de fosfato. 
O esforço de uma década do país, apoiado pelo FMI (Fundo Monetário Internacional) e pelo Banco Mundial para implementar medidas de reforma econômica, encorajar o investimento e aumentar as receitas com as exportações tem sido lento.

Portanto, a capital (Lomé) é mais povoada do país, com uma população mais de 5 milhões de habitantes. A população fixa é constituída em grande parte, por pessoas com baixo poder econômico, social e educacional, sendo que esses fatores contribuem negativamente no estabelecimento do perfil epidemiológico local que é favorecido pela aglomeração de pessoas em bairros mais pobres da Capital e ao redor sem acesso ao saneamento básico, além de estimular a existência de subempregos e atividades indignas de um ser humano, como a presença de crianças nos lixões a procura de alimento ou algo passível de ser convertido em renda.

Não obstante a coleta regular, feita pelo poder público, uma grande quantidade dos resíduos sólidos gerados vem sendo jogada a céu aberto, em terrenos baldios, córregos, estuários, mangue e praias, o que implica em risco à saúde humana e grande impacto ao ambiente, muitas vezes de forma irreversível ou quando reversível consome-se muito tempo e o custo é normalmente muito elevado.

Neste contexto, a questão social que envolve a atividade de centenas de catadores - pessoas atingidas pelo desemprego, e pelo processo mais amplo de exclusão social, retiram diariamente do lixo sua sobrevivência. Este trabalho realizase em condições bastante precárias e indignas.

Nesse sentido, foi implantado a coleta seletiva em todas Cidades do país, através da disposição de lixeiras seletivas para metais, plástico, papel e material orgânico. Após a coleta seletiva e triagem, o lixo é classificado e distribuído conforme composição química e utilidade em:

. Lixo orgânico: para o processo de compostagem e para o núcleo horta (produtos orgânicos), jardinagem e alimentação alternativa.

- Lixo inorgânico: venda de materiais para indústrias de reciclagem, matéria-prima para a oficina de criação, para as atividades artísticas, lúdicas, terapêuticas e de reabilitação psicomotora e também para os laboratórios de reciclagem de materiais obsoletos.

É importante salientar que este projeto mudou a vida dos povos da comunidade, assim, com base na coleta seletiva do lixo e no reaproveitamento de materiais, estimulou a formação de cooperativas de produção e profissionalização (capacitação dos catadores), aumentou a renda autônoma e a riqueza da própria Cidade e do país inteiro.

\subsection{MARKETING E A BIODIVERSIDADE}

Em meio a um conjunto de modificações que são observados na dinâmica de mercado atualmente, cada vez mais as organizações necessitam estar envolvidas com uma nova visão, focada numa perspectiva responsável. Para tanto, percebendo-se que as empresas podem contribuir nesse sentido em diversas áreas, identifica-se no marketing a possibilidade de mudança buscando uma melhor atuação empresarial (LAVILLE, 2009). Isso pode ser possível a partir do marketing responsável ou ambiental. Noutro sentido, discute-se o emergir do novo paradigma de consumo, o sustentável, que para ser operacionalizado uma visão política necessita também dessas interações sociais (MICHAELIS, 2003).

Sob um contexto de mudanças que são observados nas áreas econômica, social e ambiental percebe-se cada vez mais como necessária a busca por uma mudança no paradigma de desenvolvimento. Esse fato vem sendo discutido em 
busca de uma visão sustentável na qual diferentes atores, principalmente as organizações, necessitam estar atuando. Nesse sentido o maior desafio atualmente para esse processo de mudança envolve a mudar sua forma de atuação, essa perspectiva sustentável se torna facilitada pelo chamado desenvolvimento sustentável.

Este processo relacionado a questão de responsabilidade da empresa, considerando a comunicação aos públicos externos com relação ao que vem sendo desenvolvido na empresa ou com relação a sua forma de atuação, o papel do marketing surge como aspecto de interação entre a empresa, o consumidor, e por consequência os demais stakeholders, como aspecto comunicador das práticas organizacionais, isso pode ser visualizado por meio do marketing responsável. Essa nova prática empresarial facilita a interação da empresa com seu contexto a partir das ações por essa desenvolvida, o que pode contribuir diretamente para o consumo sustentável.

O marketing responsável ou verde consiste em todos as atividades que tenham o propósito de gerar e facilitar quaisquer mudanças que venham a satisfazer as necessidades e desejos humanos, contanto que a satisfação de tais necessidades e desejos ocorra com impacto mínimo do meio ambiente. Ele tem como objetivo projetar e sustentar a imagem da empresa difundido e destacando sua diferenciação ecologicamente correta junto a sociedade aos fornecedores, aos funcionários e ao mercado, viabilizando o lucro com a sustentabilidade ambiental.

Com relação à gestão do meio ambiente, a atitude humana passou a causar mais impacto negativo sobre aquilo, e o que durante muito tempo foi visto como fonte inesgotável de recursos disponíveis para servir as necessidades do homem passa agora a ser motivo de preocupação e de inquietação, visto que os recursos são limitados.

Enquanto a persistência desse fenômeno, as empresas passam a se reestruturar a nova percepção mundial. As pressões sociais e restrições impostas fazem com que as organizações sejam forçadas a buscarem formas de reduzir seu impacto ambiental e melhorar sua imagem frente a sua responsabilidade social. Autores incentivaram as iniciativas das empresas através de marketing de responsabilidade social como filantropia e patrocínio de atividades esportivas, culturais, educacionais e de cuidados com meio ambiente, o que são o coração e a alma dos negócios.

Infelizmente, as empresas só pensam em lucro, enganam os consumidores, exploram os empregados, sonegam impostos, corrompem autoridades, poluem o ambiente, são insensíveis aos problemas sociais, comandam ou participam de grandes conspirações contra a humanidade. Os benefícios gerados pelas empresas para a sociedade não são vistos, percebidos e reconhecidos pela maioria das pessoas.

Contudo, para que as iniciativas das empresas chegam aos seus stakeholders de forma consciente e produzam os efeitos desejados estas procuram desenvolver mecanismos eficientes para comunicar suas ações. Uma das formas é mostrar em seus produtos, a origem dos materiais, como são desenvolvidos os processos, possibilidades de reaproveitamento/reciclagem dos produtos em propagandas e outras ferramentas de comunicação.

Nesse sentido, um dos autores mais citado na literatura, explicou que o marketing ambiental consiste no conjunto das atividades concebidas para produzir e facilitar a comercialização de qualquer produto ou serviço com a intenção de satisfazer necessidades e desejos humanos, porém causando impacto mínimo ao 
meio ambiente. Isso envolve modificação de produtos e embalagens, bem como mudanças em processos de produção e publicidade. Sua importância se deve ao fato de as pessoas utilizarem desejos ilimitados. É baseado no pressuposto de que os consumidores querem um meio ambiente mais limpo e estão dispostos a pagar por isso.

Dadas essas características o marketing ecológico deve ter como objetivo criar uma imagem diferenciada da empresa, incluindo uma maior sensibilidade ambiental quanto aos atributos do produto e ao posicionamento da empresa com relação ao meio ambiente. (OTTMAN,1994).

O estudo das variáveis apresentadas faz com que a interação empresaconsumidor possa ser verificada claramente. Desse modo, quando uma empresa consegue readequar suas ações, melhorar sua forma de atuação e melhor apresentar informações para os consumidores, a mesma está praticando o marketing responsável. Entende-se que, sob a ótica do consumo sustentável, por si só o marketing não consegue efetivar a mudança no comportamento nem na cultura organizacional para uma perspectiva mais responsável, todavia o mesmo tem peso e importância nesse processo, já que a ligação direta entre a empresa e o mercado. Assim, as discussões realizadas se baseiam nas variáveis destacadas e procuram uma melhor atuação empresarial no contexto ao qual se está analisando.

Desse modo, no que tange ao composto de marketing responsável, para que o mesmo possa ser avaliado toma-se como parâmetro de análise que: a construção de um esforço mercadológico no que se refere a produtos, preço, praça e promoção mais responsáveis contribui para o processo de mudança cultural na rede de influências da empresa, bem como melhora sua prática responsável. De acordo com a pesquisa, no Walmart Brasil esse fato inclui a adoção de estratégias relacionadas a formatos de loja, merchandising e precificação (WALMART BRASIL, 2011). Para tanto, deve-se observar cada um dos aspectos que estão relacionados com 0 composto.

Constatou-se uma desmistificação da teoria de que o marketing verde se trata apenas de uma publicidade com apelo a consciência ambiental, e conclui-se que se constituem uma prática de abrangência global em que devem ser levados em consideração multipolos aspectos tais como: responsabilidade socioambiental da empresa em todas as suas atividades, mudanças na cultura de organização ética, trabalho constante de conscientização dos funcionários e consumidores, implementação de atributos verdes aos produtos, sendo assim, tem-se percepção ambiental como auxiliar de desenvolvimento socioeconômico e ambiental de um lugar, de boa qualidade e com uma integração ao meio ambiente.

\subsection{O FUTURO DO MEIO AMBIEMTE NA ÁFRICA}

O desenvolvimento econômico da África baseia-se na qualidade e integridade dos seus recursos ambientais. A área ambiental da região da África procurem as oportunidades para alcançar os objetivos da Nova Parceria para o Desenvolvimento da África (NEPAD). Centenas de milhões de pessoas dependem diretamente ou indiretamente desses recursos. Os governos Africanos reconhecem esse fato e colocaram em práticas as medidas para salvar esses bens preciosos, incluindo a adoção fundamental do Plano de Ação em Lagos (Nigéria) em 1980. Ele propõe medidas concretas para apoiar a correlação entre o desenvolvimento e o meio ambiente, isso estipula entre outra a necessidade que os governos africanos preocupam-se do meio ambiente e a planificação de desenvolvimento.

Os presidentes africanos criaram Conferência dos Ministros Africanos do Meio ambiente (CMAE) em 1985, visa fortalecer a cooperação regional como soluções 
políticas para o meio ambiente e de atividades técnicos e científicas para minimizar a degradação e dar interesse particular aos bens e serviços ambientais que são essenciais para realizar um desenvolvimento sustentável. CMAE, é a autoridade final sobre o meio ambiente em África desde dez anos, bem-sucedido, apesar de diversos constrangimentos em termos de recursos e capacidades a cumprir sua missão de líder regional e dar uma direção para políticas ambientais. Afim de continuar essa abordagem num contexto onde a globalização tem tido um ritmo acelerado, tem que ser uma visão dinâmica e estratégia suportado por uma base de informação sólida.

Portanto, CMAE continua a reforçar relatório de iniciativa sobre o Futuro do Meio ambiente na África (FMA) desde o lançamento em 2000, durante a 8 sessão em Abuja. AEO é um relatório importante que segue o estatuto e tendências ambientais da região e questões emergentes. Desde a publicação e lançamento de primeiro relatório em julho 2002, o planejamento estratégica na paisagem ambiental africana evoluiu. $O$ relatório ambiental ao nível nacional e sub-regional foi consideravelmente reforçado e cerca de 22 países em cinco regiões produziu seu relatório sobre o Futuro do Meio ambiente em África, utilizando a metodologia (FMA). O relatório teve uma influência considerável sobre a posição da África na Cimeira Mundial sobre Desenvolvimento Sustentável (CMDS) que foi realizado em Johanesburgo, em agosto de 2002. Ele serviu também para desenvolver a iniciativa ambiental da NEPAD (Nova Parceria para o Desenvolvimento de África) foi adotada em 2003 pela União Africano como plano para programas ambientais da região. É uma ligação indiscutível entre avaliação ambiental e decisões tomadas cujas estamos orgulhosos.

Durante os últimos quatro anos, o que tange o dinamismo gerado pelo primeiro relatório, CMDS, com apoio de Programa dos Nações Unidos para o Meio Ambiente (PNUM), elaborado no segundo relatório sobre o futuro ambiental em África- Nosso Ambiente, Nossa Riqueza (FMA-2). Ele esclarece os números de oportunidades que oferecem o meio ambiente africano para evitar a extrema pobreza e a fome, reforçar fortemente acessibilidade para a maioria dos habitantes, além disso realizar enorme progresso na implementação dos OMD (Objetivo Milênio para o Desenvolvimento).

O relatório (FMA-2) desenvolvido é uma realização das instituições e especialistas da África e ainda é prova de que a África tem os recursos Humanas e habilidades para moldar o seu próprio destino e tornar o sonho de renascimento da realidade africana. Isto, requer a vontade e o compromisso político de traduzir descobertas cientificas em ação no campo.

O novo milênio é o começo de um renascimento política, econômica e ambiental em África. A criação da Nova Parceria para o Desenvolvimento da África, NEPAD, foi um ponto de viragem e um novo compromisso com a adoção de políticas e sistemas permitindo as prosperidades da África. Os recursos naturais africanos e ambientais representam uma parte importante dessa visão em razão de seu enorme potencial para o desenvolvimento e melhoria de bem-estar. É importante, levar em consideração que o século 21 será o século da África, um século de prosperidade, paz de longo prazo e desenvolvimento sustentável.

\section{CONSIDERAÇÕES GERAIS}

Constituindo-se em um projeto multidisciplinar a atuação de profissionais e acadêmicos de diversas áreas se torna indispensável para a formação de uma equipe de trabalho. Para tanto o projeto deverá ter o envolvimento da cidade como 
um toda a comunidade. Os resultados obtidos neste estudo serão analisados estatisticamente, apresentados em encontros científicos e publicados.

- PROGRAMAS DE DIVULGAÇAO E DIFUSÃO CULTURAL: Programas de divulgação para a comunidade através de panfletos educativos, rádio, televisão ou jornal das atividades desenvolvidas pelos governos africanos.

- NÚCLEO DE ENGENHARIA, ADMINISTRAÇÃO E DIREITO: a gestão e elaboração de projetos de saneamento básico, combate às enchentes, limpeza de galerias, limpeza e vistoriais das bocas-de-lobo, preservação das margens dos mananciais e manguezais, ampliação de rede coletora e tratamento de esgoto, disposição de resíduos sólidos (domiciliares, industriais e de saúde), tratamento de água e prevenção de epidemias, canalização de córregos e canais, despoluição de mananciais, recuperação de parques e jardins, preservação das águas (superficiais e subterrâneas) e reuso industrial; incentivo ao ecoturismo; participação de indústrias e empresas na preservação ativa do meio ambiente; planejamento e formação de cooperativas, orientações sobre leis de crimes ambientais e desenvolvimento sustentável; ISO 14000; programas de redução de consumo de água, campanhas de educação ambiental e políticas públicas.

A necessidade de se introduzir a educação ambiental nos diversos país da África é de fundamental importância, pois, ela sensibiliza e forma futuros cidadãos africanos. Além de possibilitar conhecimentos e habilidades capazes de promover a sustentabilidade e melhorar a qualidade de vida da comunidade africana, desperta a necessidade de preservar o meio ambiente e conservar os recursos naturais na África, com o apoio dos governos africanos. 


\title{
TRADE AND ENVIRONMENT: The ENVIRONMENTAL IMPACT ON THE ECONOMY OF TOGO and AFRICA.
}

\begin{abstract}
:
One of the main challenges of this century has been to reconcile economic growth with environmental preservation, considering the population growth and the production of waste from disposable and industrial products. sustainable development is aiming to become necessary to adopt attitudes based on the application of the policy principles of the three (R) (Reduce, Recycle, Reuse) for the waste produced making it useful in the preservation of the environment and quality of life, appreciation of human nature, based on environmental education. The management of garbage collection in poor area aims to raise awareness, mobilize, and ongoing participation in environmental protection, such as exercise citizenship. The project aims to ecologically correct destination, reinforcing the goals of sustainable development through the recycling of inorganic waste and or reuse even through reuse process in craft workshops for the benefit of the community and reuse of organic waste through composting and generation process useful products to the Company. Moreover, show business concerns about the preservation of the environment and how is this ecological change in Africa.
\end{abstract}

Keywords: garbage, recycling, selective waste collection, environmental education

\section{REFERENCIAS BIBLIOGRAFICAS}

BRILHANTE, O.M.; CALDAS, L.Q. de A. (coord.) Gestão e avaliação de risco em saúde ambiental. Rio de Janeiro: FIOCRUZ, 1999.

BORBA, M.P., BOJADSEN, M. I. e RENAERD, M., Lixo e reciclagem, Instituto de Educação e Pesquisa Ambiental, São Paulo, SP, 1994.

LAVILLE, É. A empresa verde. São Paulo: ÕTE, 2009.

LIMA, J. D. Gestão de Resíduos Sólidos Urbanos no Brasil. ABES 267p./ 2001.

MICHAELIS, L. Ethics of consumption. Ethics \& Society. 2000a.

MICHAELIS, L. Sustainable consumption and production.

In: $\quad$ DODDS, $\quad$ F.; MIDDLETON, T. Earth Summit 2002: A new deal.

Earthscan Publications Ltd. 2000b.

OTTMAN, Jacquelyn A. Marketing Verde: Desafios e Oportunidades para a Nova Era do Marketing. São Paulo: Makron Books, 1994. 190 p.

WALMART Brasil. Relatório de sustentabilidade 2011 (Exercício 2010). 2011. 
Disponível em: <http://www.walmartsustentabilidade.com.br/relatorioonline/downloads/Walmart_RA10_pt.

pdf> Acesso em: jul. 2011. 